\title{
West Nile virus illness in Ontario, Canada: 2017
}

\author{
S Wijayasri ${ }^{1 \star}$, MP Nelder ${ }^{1}$, CB Russell ${ }^{1}$, KO Johnson ${ }^{1}$, S Johnson², T Badiani ${ }^{1}$, D Sider ${ }^{1,3}$
}

\begin{abstract}
Background: In Canada, the annual incidence rates of West Nile virus (WNV) illness have fluctuated over the last 15 years. Ontario is one of the provinces in Canada that have been the most affected by WNV and, as a result, has implemented robust mosquito and human surveillance programs.
\end{abstract}

Objective: To summarize and discuss the epidemiology of WNV illness in Ontario, Canada in 2017, with comparisons to previous years.

Methods: Case data were obtained from the provincial integrated Public Health Information System. Provincial and public health unit (PHU)-specific incidence rates by year were calculated using population data extracted from intelliHEALTH Ontario.

Results: In 2017, the incidence of WNV illness in Ontario was 1.1 cases per 100,000 population, with 158 confirmed and probable cases reported by 27 of the province's 36 PHUs. This is the highest rate since 2013, but less than the rate in 2012 ( 2.0 cases per 100,000 population). Incidence rates in 2017 were highest in Windsor-Essex County and in PHUs in eastern Ontario. While the seasonality is consistent with previous years, the number of cases reported between July and September 2017 was above expected. Most cases were in older age groups (median: 58 years old) and males (59.5\% of provincial total); cases with severe outcomes (neurological complications, hospitalizations, deaths) were also disproportionately in older males.

Conclusion: WNV illness continues to be an ongoing burden in Ontario. The increase in the number of cases reported in 2017, and the increased number of PHUs reporting cases, suggests changing and expanding risk levels in Ontario. Continued mosquito and human surveillance, increased awareness of preventive measures, and early recognition and treatment are needed to mitigate the impact of WNV infections.
This work is licensed under a Creative Commons Attribution 4.0 International License.

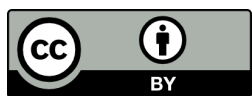

Affiliations

${ }^{1}$ Enteric, Zoonotic and Vector-borne Diseases, Communicable Diseases and Emergency Preparedness and Response, Public Health Ontario, Toronto, ON

${ }^{2}$ Knowledge Services, Public Health Ontario, Toronto, ON

${ }^{3}$ Department of Clinical Epidemiology and Biostatistics, McMaster University, Hamilton, ON

*Correspondence: shinthuja. wijayasri@oahpp.ca

Suggested citation: Wijayasri S, Nelder MP, Russell CB, Johnson KO, Johnson S, Badiani T, Sider D. West Nile virus illness in Ontario, Canada: 2017. Can Commun Dis Rep 2019;45(1):32-7. https://doi. org/10.14745/ccdr.v45i01a04

Keywords: Culex, mosquito, surveillance, epidemiology, public health, climate, West Nile virus

\section{Introduction}

West Nile virus (WNV) is a mosquito-borne pathogen of public health concern in Canada. The virus was first identified in North America in 1999, with the first human case of WNV illness in Canada confirmed in Ontario in $2002(1,2)$. The virus has since become endemic to Canada, with the annual number of cases reported nationally fluctuating over the last 15 years (reaching a high of 2,215 cases in 2007 and a low of five cases in 2010) (3). Cases have been reported in all ten provinces since 2002, with the majority occurring in the prairie and central provinces (4). Ontario (which represents approximately $38.7 \%$ of the Canadian population) has reported cases of WNV illness every year since 2002, with epidemics reported in 2002 and 2012 (2,5,6).

In Ontario, Culex mosquitoes are primarily responsible for WNV transmission to humans (7). Mosquito development, and the rate of virus replication inside the mosquito, is heavily driven by temperature and geography - they are most active in warmer temperatures and urban environments where catch basins with standing water are widespread $(6,7)$. In 2016, the majority of WNV-positive mosquito pools in Ontario were reported in the Golden Horseshoe and urban areas of southwestern and 
southeastern Ontario (7). Studies have identified a strong relationship between the number of WNV-positive mosquito pools and the number of confirmed human cases reported each year, highlighting the usefulness of mosquito surveillance in early detection and risk assessment $(6,8)$.

While the majority of cases are asymptomatic, or do not seek medical attention due to mild symptoms, a fraction of those infected develop severe outcomes, including neuroinvasive disease $(9,10)$. Neuroinvasive disease that can present as meningitis, encephalitis or acute flaccid paralysis are difficult to treat and are associated with high morbidity, mortality and long-term sequelae $(9,10)$. Considering that WNV infection can lead to severe illness, and that treatment is only supportive, public health efforts have focused on early detection through mosquito and human surveillance, promotion of preventive measures and increasing awareness (9). An understanding of WNV epidemiology is therefore necessary to inform such public health efforts.

The objective of this report is to summarize and discuss the epidemiology of WNV illness in Ontario, Canada in 2017, with comparisons to previous years.

\section{Methods}

\section{Population and surveillance case definitions}

During the 2017 surveillance period, there were 36 public health units (PHUs) in Ontario that provided local health services within their jurisdictions (11). Under the Health Protection and Promotion Act, all PHUs are responsible for case management and reporting of diseases of public health significance in Ontario (12). PHUs classify and report confirmed and probable WNV illness cases using the provincial surveillance case definitions and disease classifications (13).

\section{Data source}

PHUs report WNV illness cases to the province using the web-based integrated Public Health Information System (iPHIS). PHU reports include information on case demographics, exposures, symptoms, hospitalizations and deaths. Details for confirmed and probable cases of WNV illness with episode dates from 2005 to 2017 were extracted from iPHIS. Episode date is an approximation of illness onset, based on the first available date in the following hierarchy: symptom onset, specimen collection, laboratory result or report date.

\section{Analyses}

Descriptive analyses were conducted using SAS 9.3 and Microsoft Excel 2010. Case-level data from iPHIS were used to describe the geographic trends, seasonality, age and sex distributions and clinical outcomes of WNV illness cases in Ontario reported in 2017. To eliminate the skewing effect of the
WNV epidemic in 2012, the epidemic year was excluded from historical averages, and four-year historical averages (2013-2016) were used as comparators to 2017 (6). Provincial incidence rates (2005-2016) and PHU-specific incidence rates (2017) were calculated per 100,000 population per year using provincial and PHU population estimates (2005-2016) and projections (2017) obtained from Statistics Canada via intelliHEALTH Ontario. Given the uncertainties with assigning exposure locations, cases reporting travel outside the province during the incubation period were not excluded from the analyses. ESRI ArcGISTM $v 10.3$ (ESRI, Redlands, California, United States) was used to map WNV illness incidence rates by PHUs for 2017. Rates were grouped into classes using manual classification methods.

\section{Ethics statement}

This manuscript reports on routine surveillance activities and not research, and therefore research ethics committee approval was not required. Data are available upon request via Public Health Ontario at http://www.publichealthontario.ca/en/About/Pages/ privacy.aspx.

\section{Results \\ Overall}

In 2017, 158 confirmed and probable WNV illness cases were reported in Ontario, well above the four-year historical average of 40 cases per year. This is the second highest number of cases reported in a single year since 2005, with the number of cases increasing annually since 2014 (Figure 1). The incidence rate of WNV illness in Ontario in 2017 was 1.1 cases per 100,000 population, an almost three-fold increase from 2016 ( 0.4 cases per 100,000 population), but below the incidence rate in 2012 (2.0 cases per 100,000 population).

Figure 1: Number of confirmed and probable West Nile virus illness cases and incidence (per 100,000 population), by year, in Ontario, Canada, 2005-2017

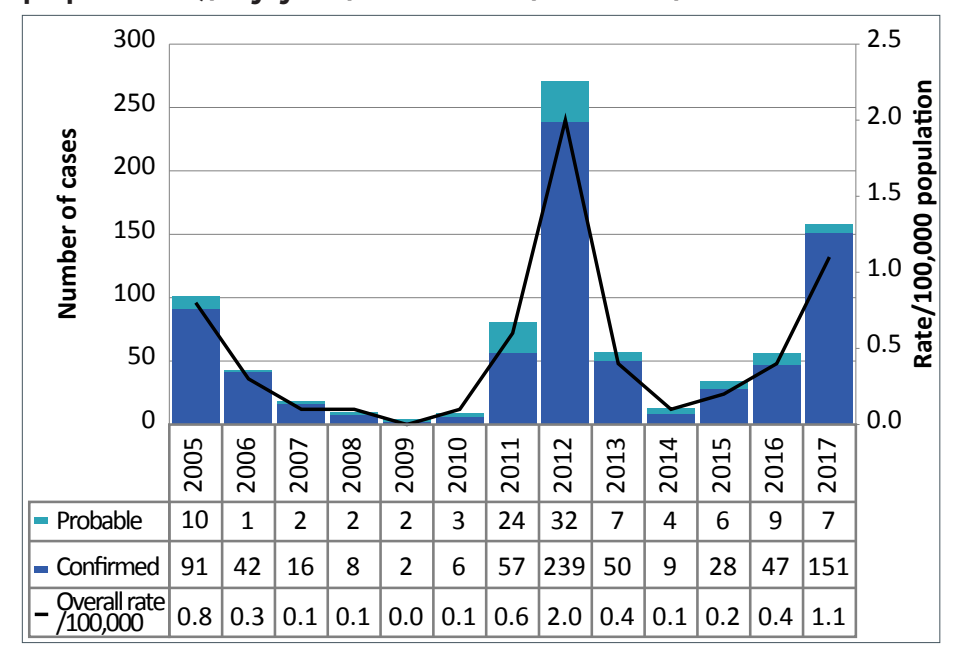




\section{Geographic distribution}

Twenty-seven PHUs reported WNV illness cases in 2017. This is higher than in the previous four years (2013-2016), during which 13 to $15 \mathrm{PHUs}$ reported cases per year. Of the total cases reported in Ontario in 2017, the majority of cases were reported by Toronto (28/158 cases, $17.7 \%)$, followed by Ottawa (20/158 cases, $12.7 \%)$ and Windsor-Essex County (20/158 cases, $12.7 \%)$. Increases in Ottawa (7.5 times its four-year historical average) and Windsor-Essex County (5.7 times its four-year historical average) were particularly notable (Table 1 ).

Table 1: Number of confirmed and probable West Nile virus illness cases reported in 2017, compared to fouryear historical averages (2013-2016), by public health unit $^{\text {a }}$ Ontario, Canada

\begin{tabular}{|c|c|c|c|}
\hline \multirow[t]{2}{*}{ Health Unit } & \multicolumn{2}{|c|}{2017} & \multirow{2}{*}{$\begin{array}{c}2013-2016 \\
\begin{array}{c}\text { Four-year } \\
\text { average }\end{array}\end{array}$} \\
\hline & $\mathbf{n}$ & $\%^{\mathrm{b}}$ & \\
\hline Toronto & 28 & 17.7 & 12.5 \\
\hline City of Ottawa & 20 & 12.7 & 2.7 \\
\hline Windsor-Essex County & 20 & 12.7 & 3.5 \\
\hline York Region & 12 & 7.6 & 1.5 \\
\hline Peel Region & 10 & 6.3 & 4.3 \\
\hline Niagara Region & 8 & 5.1 & 5.7 \\
\hline Simcoe Muskoka District & 7 & 4.4 & 1.3 \\
\hline City of Hamilton & 6 & 3.8 & 3.7 \\
\hline Halton Region & 6 & 3.8 & 1.5 \\
\hline Leeds, Grenville and Lanark District & 6 & 3.8 & 0.0 \\
\hline Eastern Ontario & 5 & 3.2 & 1.0 \\
\hline Grey Bruce & 4 & 2.5 & 0.0 \\
\hline Durham Region & 3 & 1.9 & 0.0 \\
\hline Haliburton, Kawartha, Pine Ridge & 3 & 1.9 & 0.0 \\
\hline Peterborough County-City & 3 & 1.9 & 0.0 \\
\hline Waterloo Region & 3 & 1.9 & 0.0 \\
\hline $\begin{array}{l}\text { Kingston, Frontenac, Lennox \& } \\
\text { Addington }\end{array}$ & 2 & 1.3 & 0.0 \\
\hline Sudbury and District & 2 & 1.3 & 1.0 \\
\hline Wellington-Dufferin-Guelph & 2 & 1.3 & 1.0 \\
\hline Haldimand-Norfolk & 1 & 0.6 & 0.0 \\
\hline Hastings \& Prince Edward Counties & 1 & 0.6 & 0.0 \\
\hline Lambton County & 1 & 0.6 & 1.0 \\
\hline Middlesex-London & 1 & 0.6 & 2.0 \\
\hline Oxford County & 1 & 0.6 & 1.0 \\
\hline Perth District & 1 & 0.6 & 0.0 \\
\hline Renfrew County and District & 1 & 0.6 & 1.0 \\
\hline Timiskaming & 1 & 0.6 & 0.0 \\
\hline Total (Ontario) & 158 & 100.0 & 40.0 \\
\hline
\end{tabular}

Abbreviation: $n$, number

a Public health unit refers to the individual's health unit of residence at the time of illness onset and not necessarily the location of exposure. Location of disease acquisition cannot be attributed to public health unit. Only public health units that reported cases in 2017 are included in this table $(n=27)$

bercent (\%) is the proportion of total cases reported in Ontario in $2017(n=158)$
Windsor-Essex County also had the highest incidence rate (4.9 cases per 100,000 population) in Ontario in 2017. High incidence rates were also observed in several low population health units in the eastern region of Ontario, including Leeds, Grenville and Lanark District (3.5 cases per 100,000 population), Timiskaming (3.0 cases per 100,000 population) and Eastern Ontario (2.4 cases per 100,000 population) (Figure 2). Of cases reporting an exposure in $2017,9.2 \%(13 / 141)$ reported travel outside the province during the incubation period.

Figure 2: Incidence of West Nile virus illness (per 100,000 population) in 2017 , by public health unit ${ }^{a}$, Ontario, Canada

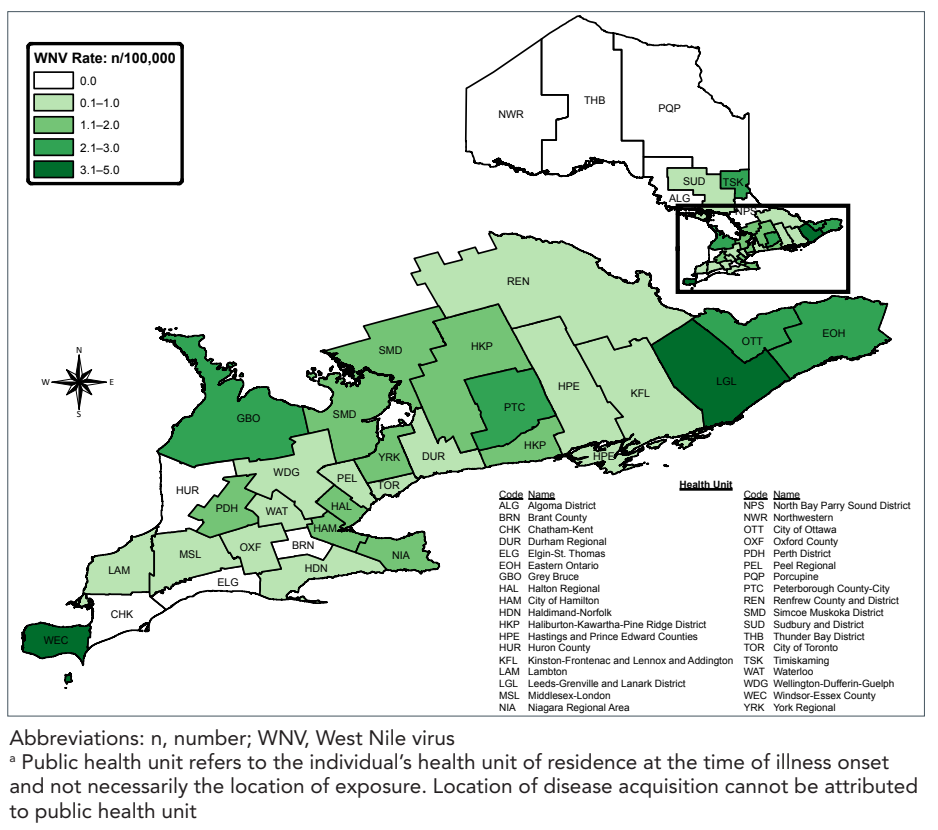

\section{Seasonality}

The majority of cases occurred between July and September 2017, with the highest proportion of cases reported in August (57.6\%) (Figure 3). The seasonal distribution of cases in 2017 was similar to previous years, peaking in August; however, monthly case counts were more than four times the average of the previous four years for July (observed 19 cases, expected four) and August (observed 91 cases, expected 17). 
Figure 3: Number of confirmed and probable West Nile virus illness cases reported in 2017, compared to four-year historical averages (2013-2016), by episode month, Ontario, Canada

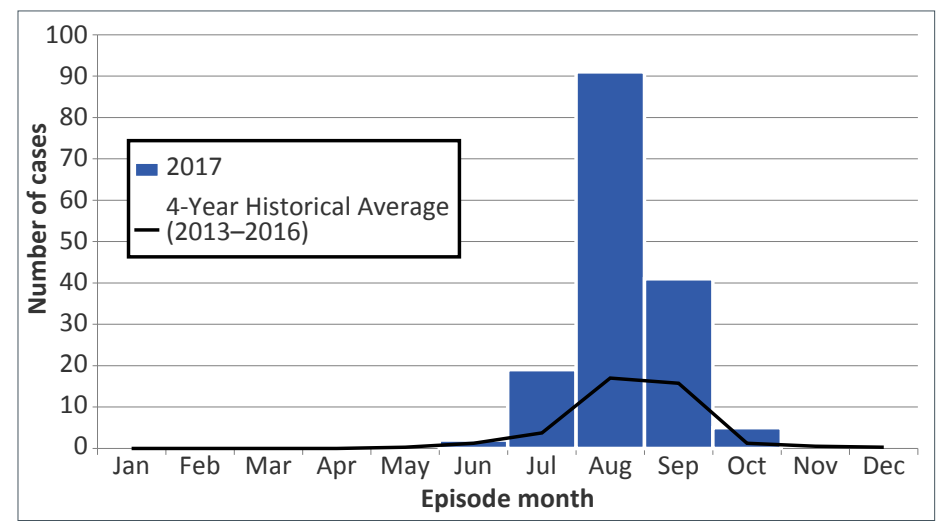

\section{Age and sex distribution}

Cases of WNV illness in 2017 ranged from five to 89 years old, with most cases in older age groups (median: 58 years old) and males (59.5\% of provincial total) (Figure 4). In particular, $50.6 \%$ of the cases reported in 2017 were $50-69$ years old and $51.3 \%$ were males over 45 years old. Overall, the age distribution in 2017 follows patterns observed in the previous four years. However, the male to female ratio was higher in the older age groups, particularly in the 40-49 (1.6 times), 60-69 (1.4 times), 70-79 (3.8 times) and the 80-89 (2.3 times) year age groups.

\section{Clinical outcomes}

Of the 158 cases reported in 2017, 38.6\% (61 cases) presented with neurological complications, 37.3\% (59 cases) presented with non-neurological syndrome, and $2.5 \%$ (four cases) were asymptomatic; illness presentation was not specified for $21.5 \%$
Figure 4: Number of confirmed and probable West Nile virus illness cases reported in 2017 compared to fouryear historical averages (2013-2016), by age groupa and sex, Ontario, Canada

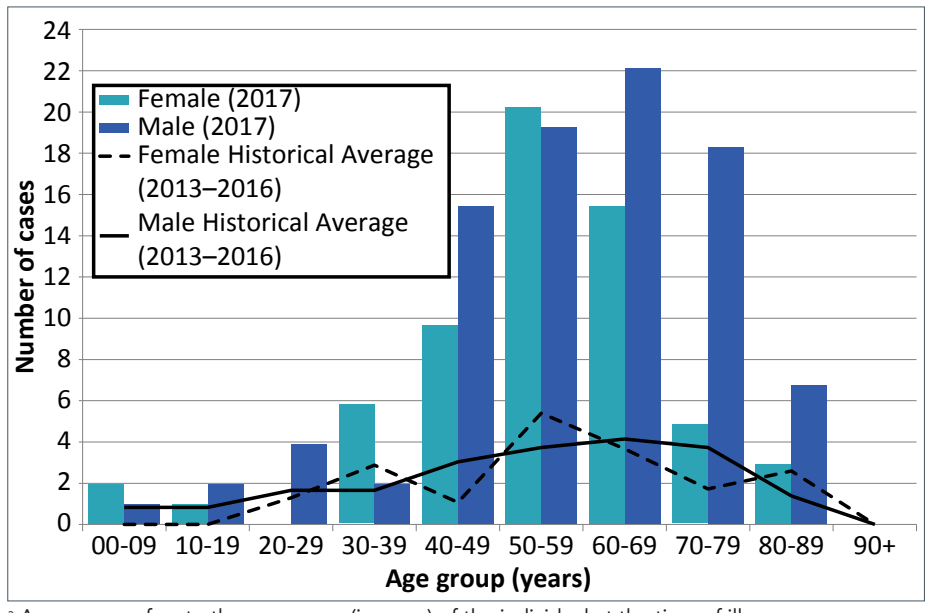

${ }^{a}$ Age group refers to the age group (in years) of the individual at the time of illness

(34 cases) (Table 2). Hospitalization was indicated for $38.6 \%$ of cases reported in 2017 (61/158), of which 72.1\% (44/61) presented with neurological complications and 14.8\% (9/61) presented with non-neurological syndrome; illness was not specified for the remaining $13.1 \%$ (8/61). The median age of hospitalized cases was 65 years old (range: $5-80$ years old), and $68.9 \%$ (42/61) were male. Of the 158 WNV illness cases reported in 2017, nine died (case fatality rate: $5.7 \%$ ), with WNV illness reported as the underlying or contributing cause for six cases (66.7\%). The median age of the nine fatal cases was 79 years old (range: $54-89$ years old) and six (66.7\%) were male. In comparison, the number of deaths reported between 2013 and 2016 ranged from zero to six per year.

Table 2: Number and proportion of confirmed and probable West Nile virus illness cases, by severity of illness and year, in Ontario, Canada, 2013-2017

\begin{tabular}{|c|c|c|c|c|c|c|c|c|c|c|}
\hline \multirow[t]{2}{*}{ Severity of Illness } & \multicolumn{2}{|c|}{2013} & \multicolumn{2}{|c|}{2014} & \multicolumn{2}{|c|}{2015} & \multicolumn{2}{|c|}{2016} & \multicolumn{2}{|c|}{2017} \\
\hline & $\mathbf{n}$ & $\%$ & $n$ & $\%$ & $n$ & $\%$ & $\mathrm{n}$ & $\%$ & $n$ & $\%$ \\
\hline Clinical Illness (all cases) & 57 & 100 & 13 & 100 & 34 & 100 & 56 & 100 & 158 & 100 \\
\hline Asymptomatic & 3 & 5.3 & 1 & 7.7 & 1 & 2.9 & 4 & 7.1 & 4 & 2.5 \\
\hline Non-neurological syndrome & 22 & 38.6 & 3 & 23.1 & 12 & 35.3 & 13 & 23.2 & 59 & 37.3 \\
\hline Neurological complications & 17 & 29.8 & 6 & 46.2 & 14 & 41.2 & 32 & 57.1 & 61 & 38.6 \\
\hline Unspecified illness & 15 & 26.3 & 3 & 23.1 & 7 & 20.6 & 7 & 12.5 & 34 & 21.5 \\
\hline Hospitalization $^{a}$ & 19 & 33.3 & 4 & 30.8 & 13 & 38.2 & 27 & 48.2 & 61 & 38.6 \\
\hline Death $^{b}$ & 2 & 3.5 & 0 & 0.0 & 0 & 0.0 & 6 & 10.7 & 9 & 5.7 \\
\hline
\end{tabular}

\section{Abbreviation: $n$, number}

a Percent (\%) refers to the proportion of total annual cases that were reported as hospitalized due to their disease at the time of data extraction; underreporting of hospitalizations may occur in

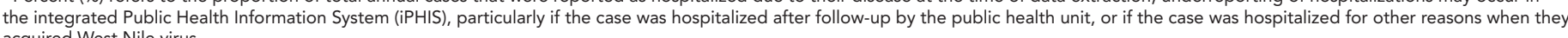
acquired West Nile virus

${ }^{b}$ Percent (\%) refers to the proportion of total annual cases for which a death was reported. Deaths were counted if the case was reported as having died due to their disease at the time of data

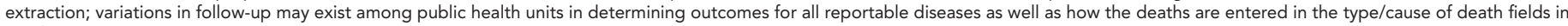
iPHIS 
disease awareness, health care seeking behaviours and variations in clinical testing. Therefore, the incidence of WNV illness is likely

The number of WNV illness cases reported in Ontario in 2017 was higher than the previous four years. This trend corresponds to trends in WNV-positive mosquito pools identified in Ontario (14). The seasonality of WNV illness in 2017 was also typical of patterns observed in previous seasons in Ontario and the United States $(2,15)$. However, while the distribution of WNV illness in urban areas of Ontario (Toronto, Ottawa, Windsor-Essex County, York Region and Peel Region) is consistent with mosquito surveillance previously conducted in the province, increases in WNV illness cases were also observed in low population, rural PHUs in eastern Ontario $(6,16)$. The age and sex distribution of cases reported in 2017 were also similar to previous years, with older age groups and males disproportionately affected. The majority of cases with severe clinical outcomes (neurological complications, hospitalizations and deaths) were also older and mostly male, consistent with previous findings that increasing age and being male are risk factors for severe WNV illness outcomes and long-term sequelae $(15,17)$.

\section{Implications and next steps}

While the cause of the increase is not immediately clear, there may some contributing factors. Ontario experienced a relatively warmer (above historical average) 2016-2017 winter, followed by average spring and early summer temperatures (18). The warmer winter temperatures allowed for increased survival of overwintering Culex mosquitoes and an increased number of WNV-positive mosquitoes in the spring and summer to start the transmission cycle $(19,20)$. This is consistent with the observation that, while the increase in 2017 was above expected, average temperatures in spring and early summer were not high enough to allow for quicker mosquito development and virus amplification to reach levels similar to $2012(20,21)$.

In terms of next steps, there are several public health implications. The 2017 surveillance period highlights the important role of robust and comprehensive surveillance data in WNV prevention and control efforts. Given that temperature is a driving factor in mosquito development and virus amplification, monitoring temperature in conjunction with ongoing mosquito and human surveillance is necessary for early detection and to assess the fluctuating risks of WNV transmission. Mosquito surveillance conducted over several years, particularly in the eastern PHUs, is needed to determine if risk levels are changing in this region and in the province. Such surveillance data are essential to informing targeted public health actions, such as increasing awareness and education related to preventive measures and early recognition, particularly in the older portions of the population and those at risk of severe disease.

\section{Limitations}

As with most passive surveillance systems, the true incidence of disease is underreported due to a variety of factors, such as underestimated, and skewed toward cases with severe clinical symptoms and outcomes. Given that the majority of WNV cases are asymptomatic or have mild symptoms, and are likely not captured by surveillance, estimating the true burden of WNV infections in the province is particularly challenging. The Public Health Agency of Canada has estimated that 18,000-27,000 WNV infections in Canada may have gone unreported or were unrecognized between 2002 and 2013 (4). As well, the geographic distributions presented in this report are based on the PHU of residence of the case at the time of illness onset and are not necessarily the location of exposure. Exposure locations reported in iPHIS (including travel-related exposure) are not sufficient to determine location of acquisition.

\section{Conclusion}

The number of WNV illness cases reported in Ontario has risen in recent years. While variations in vector biology, weather and human activity make predicting the extent and impact of WNV challenging, it is expected that as ambient temperature increases, the number of WNV illness cases in Ontario and Canada may increase. Continued and strengthened mosquito and human surveillance, public health action to increase awareness of preventive measures, and clinical care focused on early recognition and treatment, will all help to mitigate the impact of WNV illness in Canada.

\section{Authors' statement}

SW - Conceptualization, methodology, analysis, interpretation, writing original draft, review and editing

MPN, CBR - Conceptualization, methodology, analysis, interpretation, writing original draft (parts), review and editing KOJ, SJ, TB, DS - Methodology, analysis, interpretation, review and editing

\section{Conflict of interest}

None.

\section{Acknowledgements}

The authors thank Ontario's public health units for their continued commitment to West Nile virus illness case management, surveillance and reporting.

\section{Funding}

This work was supported by Public Health Ontario. 


\section{References}

1. Murray KO, Walker C, Gould E. The virology, epidemiology, and clinical impact of West Nile virus: a decade of advancements in research since its introduction into the Western Hemisphere. Epidemiol Infect 2011 Jun;139(6):80717. DOI PubMed

2. Public Health Ontario. Infectious disease in focus: West Nile virus. Monthly infectious diseases surveillance report 2012 Dec;1(13):1-14. https://www.publichealthontario.ca/ en/DataAndAnalytics/Documents/2012_December_PHO_ Monthly_Report.pdf

3. Surveillance of West Nile virus. Ottawa (ON): Public Health Agency of Canada. https://www.canada.ca/en/public-health/ services/diseases/west-nile-virus/surveillance-west-nile-virus. html

4. Zheng H, Drebot MA, Coulthart MB. West Nile virus in Canada: ever-changing, but here to stay. Can Commun Dis Rep 2014 May;40(10):173-7. DOI PubMed

5. Canada at a Glance 2018: Population. Ottawa (ON): Statistics Canada. https://www150.statcan.gc.ca/n1/pub/12 581-x/2018000/pop-eng.htm

6. Giordano BV, Kaur S, Hunter FF. West Nile virus in Ontario, Canada: A twelve-year analysis of human case prevalence, mosquito surveillance, and climate data. PLoS One 2017 Aug;12(8):e0183568. DOl PubMed

7. Public Health Ontario. Vector-borne diseases: 2016 Summary Report. Toronto (ON): Ontario Agency for Health Protection and Promotion; 2017 Jun. https://www. publichealthontario. ca/en/eRepository/Vector-Borne_Diseases_Summary_ Report_2016.pdf

8. Kilpatrick AM, Pape WJ. Predicting human West Nile virus infections with mosquito surveillance data. Am J Epidemiol 2013 Sep;178(5):829-35. DOI PubMed

9. Gray TJ, Webb CE. A review of the epidemiological and clinical aspects of West Nile virus. Int J Gen Med 2014 Apr;7:193-203. DOl PubMed

10. Patel H, Sander B, Nelder MP. Long-term sequelae of West Nile virus-related illness: a systematic review. Lancet Infect Dis 2015 Aug;15(8):951-9. DOl PubMed

11. Ontario Ministry of Health and Long-Term Care. Health services in your community: Public Health Units. Toronto (ON): Government of Ontario. http://www.health.gov.on.ca/ en/common/system/services/phu/locations.aspx
12. Government of Ontario. Health Protection and Promotion Act. R.S.O. 1990, c. H.7. R.R.O 1990, Regulation 569: Reports. 2018 May 1. https://www.ontario.ca/laws/ statute/90h07

13. Ministry of Health and Long-Term Care. Infectious Disease Protocol: Appendix B: Provincial Case Definitions for Reportable Diseases: Disease: West Nile Virus Illness. Toronto (ON): Government of Ontario; 2017 Mar. http:// www.health.gov.on.ca/en/pro/programs/publichealth/oph_ standards/docs/wnv_cd.pdf

14. West Nile virus surveillance. Surveillance week 43 (Oct 21-Oct 27, 2018). Provincial trends. Toronto (ON): Public Health Ontario. https://www.publichealthontario.ca/en/ DataAndAnalytics/Pages/WNV.aspx

15. Lindsey NP, Staples JE, Lehman JA, Fischer M; Centers for Disease Control and Prevention (CDC). Surveillance for human West Nile virus disease - United States, 1999-2008. MMWR Surveill Summ 2010 Apr;59(2 SS02):1-17. PubMed

16. Beroll H, Berke O, Wilson J, Barker IK. Investigating the spatial risk distribution of West Nile virus disease in birds and humans in southern Ontario from 2002 to 2005. Popul Health Metr 2007 May;5(3):1-16. DOI PubMed

17. Lim SM, Koraka P, Osterhaus AD, Martina BE. West Nile virus: immunity and pathogenesis. Viruses 2011 Jun;3(6):811-28. DOl PubMed

18. Climate Trends and Variations Bulletin. Ottawa (ON): Environment and Natural Resources. https://www.canada.ca/ en/environment-climate-change/services/climate-change/ science-research-data/climate-trends-variability/trendsvariations.html

19. Dohm DJ, Turell MJ. Effect of incubation at overwintering temperatures on the replication of West Nile Virus in New York Culex pipiens (Diptera: culicidae). J Med Entomol 2001 May;38(3):462-4. DOI PubMed

20. Reisen WK, Thiemann T, Barker CM, Lu H, Carroll B, Fang $Y$, Lothrop HD. Effects of warm winter temperature on the abundance and gonotrophic activity of Culex (Diptera: Culicidae) in California. J Med Entomol 2010 Mar;47(2):230_ 7. DOI PubMed

21. Dohm DJ, O'Guinn ML, Turell MJ. Effect of environmental temperature on the ability of Culex pipiens (Diptera: Culicidae) to transmit West Nile virus. J Med Entomol 2002 Jan;39(1):221-5. DOI PubMed 